\title{
Landscaping: teamwork and integration into inter-individual coordination as a learning situation
}

\author{
Patrick Mayen ${ }^{\mathrm{a}^{*} \text {, and Paul Olry }}{ }^{\mathrm{b}}$ \\ a Agrosup Dijon, Département des sciences humaines et sociales, Bd Petitjean, BP 87999, 21079, Dijon Cedex, \\ France \\ ${ }^{\mathrm{b}}$ Agrosup Dijon, Département des sciences humaines et sociales, Bd Petitjean, BP 87999, 21079, Dijon Cedex, \\ France
}

\begin{abstract}
One of the dimensions of work that is not well known in training is teamwork and the work of the team leader. The team leader is the personne who provides local supervision. Teachers and trainers, as well as business employers aknowledge the place and importance of teamwork and the role of the team leader. However, most consider themselves, insufficiently prepared to offer training in line with these elements. This paper thus aims to present the results of an analysis of group work in the field of landscaping conducted from the perspective of team work and team leader learning and training.
\end{abstract}

Keywords: professionnal didactics - team work - team leader - learning situation

\section{Introduction : teamwork and the work of team leaders : an issue for training}

One of the dimensions of work that is not well known in training is teamwork and the work of the team leader. The team leader designates the person who provides local supervision. Team leaders usually work with the members of a small team (one to five people).

Teachers and trainers, as welle as business employers and representatives, acknowledge the place and importance of teamwork and the rôle of the team leader. However, most consider themselves insufficiently prepared to offer training in line with these elements.

For example, the professionnal framework of the vocational diploma in landscaping (baccalaureat professionnel "aménagements paysagers") [1] devotes one activity class out of six to "supervising a team". This activity class in turn breaks dowm into seven main subcategories : "1/coordinates the team's activity, 2/ oversees the propoer completion of work, evaluates the work's conformity to plans, 4/ leads the team, 5/identifies personal problems and strives to maintain a positive work environment, 6/ contributes to the training and/or integration of trainees, apprentices, occasional employees, or new recruits within the business, and 7/ manages the means at the disposal of the team on the project site."

Only categories (1) and (2) provide specific details. Subcategory (4), "leads the team" is the only one that contains no details at all. The other points generally have to do with managing means and evaluating the work's conformity to requirements. Subcategory (1), "coordinates the team activity", specifies that the team leader "introduces the group to the project and defines the objectives, allocates tasks, and gives instructions related to work and safety, as well as environment risks." Subcategory (2), oversees the proper completion of work", specifies that the leader "sees to application of safety mesures, the followinbg of regulations, and the respect of the brand image of the business, answers the questions of team members, provides a demonstration if needed and carries out appropriate procedures in case of a work accident." In addition, when the leader evaluates (3), he or she "cheks on the execution and quality of work."

Several comments can be made here :

\footnotetext{
*Corresponding authors. Emails: patrick.mayen@educagri.fr, p.olry@agrosupdijon.fr
} 
- the description of the team leader's work remains general, very much anticipated and prescriptive,

- $\quad$ although the description of the team leader's activities holds an important place in the professionnal framework of the degree program, almost no space is devoted to abilities and competencies in the evaluation and training frameworks. The dimension of coordination disappears in favor of the material organization of conditions for project completion. Hence we encounter the difficulties pointed out by trainers and teachers - as well as the designers of these trainings- concerning the work, the competencies in line with coordinating a work team, and the training that mignt prepare individuals for this coordinating function,

- a very hierarchical conception or the team leader's role can be identified. The other members are executants or "agents". It is the team leader that organizes and evaluates, as welle as divides up tasks. Coordination is, in sum, centralized. The team leader appears as a conduit for transmitting objectives, rules and prescriptions defined by a superintendant. This point is reiterated a number of times in the documents,

- many points in the professional, evaluation, and training frameworks relate to technical operation in the project site. This notion of operation is understood in a dynamic sens and involves constant operations of evaluation and progress monitoring, as well as adjustment, throughout a given task,

- $\quad$ on the other hand, no link is made between the progression of the team work and the progression of the technical task,

- finally, teamwork itself is never mentioned as such.

In training, the learning of these elements comes under the responsibility of several teachers or trainers; trainers in technical fields, in communication, in economics and in management. But most of those who occupy these positions declare that they do not know how to teach these abilities. They relate their unawareness of this part of the work and the difficulty of formulating, describing, and identifying the knowledge and abilities involved. They also state the fact that this knowledge and these abilities do not correspond to their respective areas of expertise and teaching.
In many cases, learning to work within a team is not adressed by teachers and trainers. It is commonly admitted that teamwork needs to be learned in a professional situation. At the same time, trainers, teachers and employers observe that accomplishing work in a situation is not always suitable. For young professionals in training, it is wagered that participation in group work can ensure the learning of group work, as well as renforce the individual learning.

As a result, one can note that there is insufficient knowledge of the learning and competencies of the team leader's work, of aspects of work and competencies in line with the component of coordinating inter-individual work, and of the conditions and processes by whiche professionals learn to coordinate their activity. These aspects are dealt with here essentially from the angle of action and the cognitive forms of its organization. They can be structured by the following questions : in a context where traininsg is interested almost exclusively in tasks from an individual perspective of work and competencies, does group work change the nature of this work? How so? How does it affect or not the complexity of the work, the mode of action and representation? How does it promote or not learning and what types of learning within a situation?

This paper thus aims to present the results of an analysis of group work in the field of landscaping conducted from the perspective of training.

\section{A professionnal didactics analysis of teamwork : methodological and theoretical aspects}

To specifically analyze the work of the team leader, this paper examines the activity of the individual acting as team leader, but also the activity of the team in which the leader's action takes place. Work psychology and ergonomics offer numerouos studies and theoretical propositions on the subject of group work and the processes by which coordination is constructed and carried out. One of the paths that can be taken to analyze and understand the work of the team leader is to examine the idea that the leader's function consists in handling a part of the coordinationrelated activities. In this vein, we can read and interpret the work of the team leader based on research on coordination in group work. A few texts by Leplat [3] and Savoyant $[6,7]$ contain many resources in this regard.

This paper primarily deals with the analytical model proposed by Savoyant [6] based on the activity theory developed by Galperine [2]. This last author distinguishes between three types of 
distinguishes between three types of operations according to their function within action :

- operations of orientation that ensure analysis of the specific conditions of action, identification of the features of the object of action, and the linking of these conditions and features with the operations of execution and control that they determine. Savoyant underlines that, of the three functions, orientation is the most essential,

- operations of execution that ensure actual transformation of the object of action,

- operations of control that ensure that the progression of action is consistent with what is desired and that the product obtained corresponds to the targeted goal.

For this analysis, we will distinguish three aspects of inter-individual coordination : its forms (the types of relations between the actions that are coordinated), its conditions (what the coordinated accomplishment of actions and operations implies in terms of individual representations), and its means (the way coordination is actually carried out).

The work analysis was conducted using a profesional didactics approach. It was done by three small groups of teachers or trainers specializing in the field of landscaping. The work analysis was supervised by a teacher-researcher specialized in professional didactics who had, in fact, conducted previous research on the functions of supervision and proximity in other professional areas.

The method consisted in observing and filming three work groups in three landscaping projects typical of projects in this field and corresponding to three meaningful situations. Each team included a young worker in training. The observations were accompanied by interviews held before, during, and after the work in question. The objective was to define the work, the activity of cooperation in and by the team, and the specific activity of the team leader, on one hand; and the activity of the young workers and their integration over the course of the work, to varying degrees, on the other. Three projects were analyzed for three teams: hedge maintenance for an individual customer, roadside seeding on the outskirts of a city, and flower planting on a roundabout.

The objective was to become familiar with this work by observing it within a situation. The concerns of teachers and trainers were as follows: to analyze the functioning of teamwork; to analyze the place, role, and activity of team leaders; to identify the forms of conceptualization at play within the work and its coordination; to understand the activity of the young workers; and to determine the potential for learning in professional situations [4] [5].

\section{The analysis of teamwork and of the team leader's work}

The teams were small (three to five people, including the team leader). Each had a team leader. Their work constituted group work according to several criteria:

First, one must think in terms of the project, which represents a meaningful unit - a circumscribed space, a task to complete, a fixed amount of time, a name (roundabout planting, roadside seeding, hedge maintenance), and, finally, a team and technical means allocated for the project. According to the classification of Leplat, the chantier or project corresponds to "the prescribed group task or task to complete ... the one that the organization seeks to accomplish" [3].

This constitutes group activity since, in the words of Leplat, "the execution of a task involves the coordinated intervention of several operators.... The activity is collective and coordinated: the operators interact, that is, their activities depend on one another." However, this definition cannot be applied to all that takes place during the project. A project could even be completed by a single person. Moreover, many tasks are carried out individually. What defines projects as situations of group activity relates to the constraint of completion in a limited amount of time, as well as efficiency from an organizational standpoint, as all project sites create inconveniences for customers and users. The need for coordination hence does not come only from the task itself, strictly speaking (what needs to be done, the objects and phenomena to act on and with, the instruments to use - notably, in this case, machines to drive). It also stems from a socially and organizationally situated task, primarily in terms of time constraints for the customer or users, as well as productivity.

We can thus see that the area of landscaping projects is one in which it is possible to contribute to a project divided up into individual tasks, provided that coordination is ensured, either by the team leader, or by team members as in the case of the roundabout planting. In this last project, three workers participate. One seems to take on all of the tasks "surrounding" those properly related to the planting: securing the project site, driving and unloading the truck, recover- 
ing containers emptied of their plants. The two others see to the flower planting itself. They establish the composition, adjust it, and do the planting.

In the roadside seeding, progress is quite impressive since six workers work together while each completing a different task. These tasks succeed and complement one another to produce the end result (seeded roadsides) as things advance. This strategy is justified by a constraint to move forward more quickly than the encroaching threat of rain. When one part of the work is completed, the rain ceases to have a bearing. On the other hand, it can cause damage or trouble when it comes during the intermediate stage of an operation. In this context, the work, even if carried out by a combination and succession of individual tasks, is collective. Here again, it is the situation that creates the requirement of group work.

In this same seeding project, it can be seen that the environment in which the task is completed accounts for some of the operations of orientation for each of the individual tasks: there is a clearly defined tracing, the rhythm is provided by the team leader's work and by the progression of the others' work, the previous task produces a state that needs to be continued, and the next task needs to be prepared. The individual that intervenes afterward is also likely to control and evaluate the results of each individual task. In this form of coordination, a part of orientation operations can be considered to be assumed by the activity of the team leader, by the very nature of the organization of the collective task's progression by portions of the project site, by the guideposts provided by the tracing, and by the state of progression of the project itself. This appears to facilitate guidance and the maintaining of attention to each of the individual tasks, and also seems to ensure a certain fluidity and definite efficiency. Nevertheless, even if mutual adjustment seems to suggest an environment favorable to the integration of new workers in this work, the question arises of whether this environment might hold limited potential for learning. This work requires no participation in operations of orientation specific to completing the overall task, or even precludes participation in them.

However, as in the hedge maintenance project, the team leader also coordinates the work by organizing a rotation of team members for all tasks. This is done for two main reasons: first, tasks vary in the extent to which they are unpleasant, gratifying, or repetitive, as well as physically difficult and tiring. They also all require a high level of concentration and sustained effort to be completed consistent with the quality criteria set down in the book of specifications, as well as those personally established by the team leader. These include driving machines precisely to within centimeters; respecting slopes, alignments, and evenness; leveling surfaces; respecting limits; and implementing minimal phytosanitary treatments. Rotation offers a way to boost concentration, but also a way to change motions and postures, thereby reducing physiological tensions. It also ensures fairness between the members of the team.

In all three projects, the team leader actively participates in carrying out the tasks in two senses: doing the work like the others, and providing an activity of coordination.

The team leader takes on unpleasant or delicate tasks like the other team members in the hedge maintenance project, and even more than the others in the roadside seeding project. In the seeding project, the team leader participates in the rotation of workers for tasks, but does not drive the available machines. This leader works on tasks done using basic manual tools. The choice is explained by the fact that the workers prefer to drive the machines, since this is more gratifying and less tiresome. It is also justified by the possibility of conducting, at the same time as the leader's other tasks, operations relative to orienting and controlling the overall task of project completion, or even the activity of each worker. In other words, the leader carries out a task in the collective distribution of tasks, in addition to coordinating and leading the project. We can thus see that the leader gives the tempo at the heart of the project. This is not a tempo imposed from the outside; it is given by the leader's own work rhythm. The leader also controls the progression of work. This would be impossible while driving a machine, since the attention required for driving would preclude the ability to provide the tempo, carry out control operations, and guide a driver through challenging spots.

Although the work is coordinated in such a way that workers are led to find themselves in a situation of individual activity, moments can be observed in which group work intervenes. We could briefly cite all of the tasks in which interdependence is needed: mounting a scaffold, transporting certain loads, guiding another worker in a task that requires a second point of view (when adjusting the height of a hedge, driving a machine through a challenging spot, etc.).

It is also possible to identify gatherings at the beginning of the project when work is divided up and the main tasks are established: what to do, using which precautions, which points of attention, which criteria for quality. Finally, we can identify gatherings that take place when a problem or need for ac- 
tivity orientation or re-orientation arises. The notion of gathering refers to the coming together of some or all members of the team at a particular point in the work space, a point from which examination of the problem or project seems optimal. During these gatherings, the problem is solved collectively, even if the team leader is led to approve the decision that is made and to redefine and reallocate tasks. One can also observe the use of motions related to rest: workers relaxing, bending, stretching, and leaning all while contributing to or assisting the collective activities of orientation.

Before going into detail on the nature of these activities, let us come back to the roundabout planting project. The two workers tending to the planting can be seen putting flower bed containers where the flowers will be planted and thus establishing the composition. This composition involves occupational rules regarding the distance between plants, the distribution of species, and the arrangement and division of volumes. Following rules for action is not enough, however, to complete planting for the entire roundabout in one stretch. Although the workers each compose their own space, we can see that at certain times, one of the two will stop and step back to get a sense of the global effect being produced. The other will then stop and both will get together, examine the effect they have produced together, confer, make adjustments, and resume work.

It is therefore apparent that coordinating operations of orientation in line with the project as a whole can be accomplished by the team. Observation of the team leader reveals that this individual permanently carries out operations of control, as described previously. The progression of a task (or project) in the field of landscaping is unusual: the work produces a perceptible transformation in the environment. However, the ultimate effects only appear at the end of a project (or part of a project). In addition, although there is a more or less elaborate or formalized plan according to the project, the work does not consist only in executing tasks according to this plan. The project owes its progression to gradual adjustments that bring the work closer to a result. The plan can be modified or corrected. This is what explains gatherings for controlling and reorienting action. In the hedge maintenance project, it is apparent that the size seen from the left is not the same as the size seen from the right. It is the team leader who-by stepping back as he frequently does-is placed at the right distance to see the greater whole and determine the problem. But it is together with the workers that decisions of adjustment are made. In this way, cuts are identified as being too deep and requiring adjustment, even if the adjustments are handled by the team leader.

One might think that such potential for error could be anticipated by the work of tracing and establishing reference marks (garden lines, for example). But on site, the hedge can be complex: very tall, spanning several dozen meters, irregular, neglected for three years, lined with trees in some places, poorly maintained in its beginnings. Part of the risk of error can only be revealed over the course of the project, for to discover difficulties one must clear away obstacles, and sometimes this can mean too much clearing. Moreover, the rhythm of work does not allow frequent pauses and stepping back (literally speaking), which would result in a loss of time, especially since these courses of action require workers to descend from the hedge or scaffolding. In this project, the team leader works at ground level, making it easier to take a distance and examine the bigger picture. The leader nevertheless also works, in addition to acting as supervisor.

\section{Discussion and conclusions}

Two levels of action can be identified: action in line with individual tasks distributed on the project site, and the more general action of carrying out the project, which in this context is primarily the responsibility of team leaders.

\subsection{Coordination in terms of individual tasks}

From this standpoint, work can appear less complex and tasks can seem possible to realize at a lower level of reasoning. According to the categories of Savoyant, action can take place at the level of its execution.

Workers are polycompetent because they master all of the tasks needed to see the project through. They can thus move from one task to another, and this helps to provide a certain balance of relationships within the group; the same is true when it comes to fatigue, tiresomeness, and boredom on the one hand, and attention and focused effort on the other. The same also holds for dividing up gratifying work between all team members. From the standpoint of productive efficiency, these various elements contribute to maintaining attention and the tempo of task completion. 
A sequencing of tasks can also be noted. Attention, in this case, is focused on the immediately preceding task since it guides the completion of the next one. Attention is also focused on the immediately following task, since its completion prepares the way for the work of a colleague. The idea that knowledge of the work of others is a condition for coordination, developed notably by Leplat, does not pose a problem in this type of team of qualified workers. From the standpoint of maintaining competencies, rotation and coordination hold considerable potential.

\subsection{The coordination of group activity}

Coordination is mainly provided by team leaders. In this context, the fluidity resulting from the leader's organizational and orienting responsibility (in terms of goals and actions to reach them, information gathering, orientation, and control) favors integration into the team and coordination, since concentration is circumscribed to a limited work area. This promotes the integration of new individuals into the workflow, through participation to moving tasks.

On the other hand, one can question the learning potential or the maintaining of competencies related to carrying out a project as a whole, assessing its state of progression. This issue applies to both experienced professionals and novices entering a team. The learning potential and potential for participating in orientation and control operations essentially lies in the gathering phases: the team members can then take part in the activities of project evaluation and progress assessment. Reorientation activities correspond to the redefinition of goals, actions to execute, criteria for controlling action, but also the possible redistribution of tasks in the team. However, exchanges appear to indicate that coordination-related interaction is focused more on forms of diagnosing that favor indicators of conformity to expected criteria, or decision-making scenarios in view of adjusting goals and actions - and actions to goals and conditions-even if the more fundamental phenomena specific to plants are not referred to. Concepts and indicators in line with the dimensions of service (services provided to users for workers and municipalities, or to customers for private businesses) are, conversely, frequently mentioned. The effect for customers or users, their expectations, is integrated into diagnostic activities. Related indicators of balance and aesthetics are similarly integrated (balance between physical volumes, colors, etc.; regularity, evenness, etc.).
Important differences can be seen in the integration of young workers over the course of the team's work. Their place can be more or less marginal and thus offer greater or lesser potential for learning. In the hedge maintenance project, the young worker is quickly given relatively simple tasks, but this is in part owing to reasons of limited physical endurance and limited ability to use instruments such as hedge trimmers. Within a short time the worker can no longer hold the instrument safely and efficiently, using a posture that will prevent musculoskeletal problems. In the roadside seeding project, the novice can only be given tasks involving the use of nonmechanical instruments, since the individual is not yet able to drive machines while following the work rhythm; even so, the trainee struggles to keep up with this rhythm, for reasons of endurance and ability. The new worker therefore does not fully participate in rotation and thus execute and practice all tasks. We can see, as a result, that learning potential is limited because of the constraints of project efficiency, the current state of physical abilities, and technical abilities.

Integration into work also results from two other factors. First among these is the role of the team leader with regard to the team and the young professional. The second has to do with the conditions whereby the level of piloting inter-individual coordination is made perceptible and accessible to the new worker. This new worker either stays at the level of coordinating the execution of tasks; or, by various means, reaches the level of piloting coordination through goals, phenomena, principles, and concepts. In this regard, the brief duration and limited number of gatherings appear to be insufficient. This argues in favor of organizing supervised tutorials or ensuring a greater treatment of these aspects by training outside of work.

\section{References}

[1] Référentiel de Diplôme Baccalauréat Professionnel «Aménagements paysagers $»$. Ministère de l'Alimentation, de l'Agriculture et de la Pêche. Juin 2010

[2] P. Galpérine, Essai sur la formation par étapes des actions et des concepts, in Recherches psychologiques en URSS, Moscou : Editions du progrès, 1966, pp. 114-132.

[3] J. Leplat, Ergonomie et activités collectives, in : F. Six \& X. Vaxevanoglou, Les aspects collectifs du travail. Actes du XXVII ${ }^{\circ}$ Congrès de la Société d'Ergonomie de Langue Française, Toulouse : Octares, 1993, pp. 7-28.

[4] P. Mayen, Des situations potentielles de développement, Education Permanente 119, 1999, 65-86. 
[5] P. Mayen, Apprendre du travail collectif, Travail et Apprentissages, 5, (2010), 55-72.

[6] A. Savoyant, Définition et voies d'analyse de l'activité collective des équipes de travail. Cahiers de psychologie cogni- tive, 4, 3 (1984), 273-284 \& Travail et Apprentissages, 5, (2010). 108-118.

[7] A. Savoyant, (1985). Conditions et moyens de la coordination de l'activité collective dans une équipe de travail. Le travail humain, 40, 1 ( 1985). 